\title{
Cultura, significação e afetividade
}

\author{
Katia de Souza Amorim \\ Editora convidada
}

\begin{abstract}
Historicamente, em função de sua história de constituição e marcada por paradigmas cartesianos e positivistas, juntamente com outras áreas do conhecimento, a Psicologia herdou fortemente uma concepção de ser humano, em que cognição e emoção são vistas como cindidas. Tal ideia foi discutida por Esperidião-Antonio et al. (2008), que afirmaram ser o período entre a segunda metade do século XIX e princípios do século XX marcado pelo interesse científico voltado para os processos cognitivos. Nestes estavam incluídas as atividades mentais relacionadas à aquisição de conhecimento e conectadas ao raciocínio e à memória. Esse anseio elucidativo relacionava-se à suposta maior comensurabilidade da cognição, levando ao desenvolvimento da chamada "revolução cognitiva". Para eles, poucos autores se voltaram às emoções e, ainda, concebiam-nas de modo segmentado, tratando os circuitos emocionais como eventos à parte e independentes.
\end{abstract}

De forma semelhante, Oliva et al. (2006) afirmaram, na primeira metade do século XX, que na busca de objetividade e status científico, a Psicologia adotou modelos inspirados nas ciências físicas. Entretanto, as emoções e todos os seus parentes - ou tudo que é sentido foram lançadas à margem da hierarquia de interesses ou inteiramente desqualificadas. Excluiu-se, portanto, a emoção como um tópico de pesquisa. Com isso, a ciência cognitiva apresentou a tendência para separar a cognição (razão) e a emoção, colocando-as como contrastantes e em luta pelo controle do psiquismo humano. Em vista desta tradição, somando-se à ideia de manter a objetividade para estudar a "caixa preta" da mente, a estratégia adotada por cientistas foi estudar a racionalidade independentemente das emoções. Consideraram, assim, que os estados mentais subjetivos não constituíam temas adequados de estudo.

A emoção chegou a ser considerada como "o lado sombrio e nebuloso da natureza humana" (Leite, nesse número). Dede maneira dominante, a afetividade permaneceu muito tempo como periférica no estudo dos processos humanos. Os afetos emergiram, então, como algo que não poderiam se tornar objeto de estudo científico.

Porém, a partir de outros paradigmas teóricos, a cognição e a emoção passaram a ser entendidas como indissociáveis. Por exemplo, a Psicologia evolucionista transformou o estudo das emoções de figurante em protagonista, já que muitos autores não identificam cognição com pensamento, mas consideram cognição tudo o que é mental. Não escrevem sobre efeitos das emoções sobre a cognição, porque para eles cognição refere-se a todas as operações do cérebro, incluindo emoções e raciocínio, e não um subconjunto de operações. Nessa visão, para Oliva et al. (2006), emoção e cognição são faces da mesma moeda e não moedas diferentes. As emoções são compreendidas como forças impulsionadoras das relações e desenvolvimento, inclusive de capacidades cognitivas. Nesse mesmo movimento, outros diferentes campos da psicologia - incluindo-se aí as neurociências, a fenomenologia e algumas correntes sócioculturais e construtivistas - passaram a colocar a emoção e a afetividade como foco de pesquisa.

Em função de pressupostos e questões de estudo próprios, alguns desses campos abordaram a emoção e a afetividade em uma perspectiva mais biológica, como respostas autonômicas, endócrinas e motoras esqueléticas, que dependem de áreas subcorticais do sistema nervoso e as quais preparam o corpo para a ação (EsperidiãoAntonio et al., 2008). Apesar de abordarem a temática a partir de uma perspectiva sistêmica em redes, restringiram-se aos sistemas biológicos humanos isolados (no corpo humano), deixando de apreender emoção e afetividade de forma relacional e contextualizada socioculturalmente.

Contrapondo-se a isso, Mendes e Seidl Moura (2009) que encaminharam a discussão em sentido contrário. Elas afirmaram, que o desafio da Psicologia do Desenvolvimento contemporânea é considerar a ativação de um 
sistema de emoção como relacionada a vários sistemas, dentre eles as interações e os vínculos estabelecidos. Assim, ao discutirem essa temática em relação ao bebê, salientaram que à medida que o bebê passa a perceber e antecipar comportamentos emocionais dos outros e a atribuir-lhes significados, as interações afetivas são vistas como contexto privilegiado de desenvolvimento.

Os aspectos inatos com os socioculturais, conforme a psicogenética de Wallon, foram salientados por Galvão (2001), em seu diálogo com estudos sobre a emoção e suas expressões. A interação social é apresentada como condição indispensável para a aprendizagem e para o desenvolvimento, sendo que as pessoas do entorno representam mediadores da ação sobre o ambiente. A vida emocional seria a primeira condição das relações interindividuais, pois a emoção estaria também na origem da atividade representativa e, portanto, da vida intelectual (Galvão, 2001).

O lugar do social e do relacional na análise da emoção pode emergir por meio de processos comunicativos, conforme apontado por Garvey e Silva (2010). As emoções seriam assim concebidas como relacionais e como emergindo por meio das dialógicas relações. Contribuem para pontuar a posição da pessoa no dinâmico fluxo de comunicação. No dialogismo da relação, a pessoa corporificada se sintoniza em relação ao outro por meio de várias experiências emocionais. Levam-se à abertura ou ao fechamento em relação aos outros, conectando-se ou se desconectando, em um processo chamado de ressonância afetiva (Garvey \& Silva, 2010). A emoção aparece, portanto, dentro de um campo que busca apreender as emoções através das relações que se estabelecem, mostrando-se social, cultural e impressa entre as pessoas.

Portanto, a partir de alguns paradigmas teóricos, passa-se a considerar a emoção não só como devendo ser investigada de maneira interligada ao outro social, ao contexto e à cultura, mas entendendo seus elementos como indissociáveis e em relações íntimas entre si. A emoção é entendida como base da afetividade que se desdobra, passando a ser vinculada a processos relacionais e culturais - tanto a nível macrossistêmico como microssistêmico, como na família, na escola, dentre outros contextos sendo base para a própria constituição do ser humano.
Foi a partir desse enfoque que integrantes do Grupo de Trabalho Contextos Sociais de Desenvolvimento: Aspectos Evolutivos e Culturais, ligados à Associação Nacional de Ensino e Pesquisa em Psicologia (ANPEPP), elegeram o tema como tópico de discussão. E, a partir de suas pesquisas - com abordagens/participantes/procedimentos metodológicos diversos -, colocaram em diálogo o objeto em questão. Como resultado dessa discussão, quatro artigos foram redigidos e articulados em forma de dossiê, buscando dar visibilidade à relevância do tema e a algumas formas de abordá-la. Assim, Amorim e colaboradoras abordaram, neste dossiê à Revista Temas em Psicologia, a questão a partir da observação de bebês. Souza analisou relatos de crianças de 4-11 anos. Leme, Carvalho e Jovelevithz trabalharam a partir do auto-relato em resposta a questionários de préadolescentes. e, Leite investigou a temática a partir de entrevistas de professores.

No trabalho de Amorim e colaboradoras investigaram processos de significação em bebês, em suas relações afetivas e nos vínculos (des)(re)(co)constituídos, com base em perspectiva histórico-cultural, a qual considera a capacidade de significação como condição especificamente humana. $\mathrm{O}$ foco foi dado através do comportamento de choro, e a partir de estudos de casos múltiplos exploratórios, longitudinais e em contextos diversos (casa, creche, abrigo), realizados com videogravações e entrevistas. Destaque nas análises vai para as significações e práticas dirigidas aos bebês que eram bastantes diversas em função dos modos de construção de vínculos, nos contextos específicos. Nesse sentido, as autoras verificaram que as significações eram vivenciadas por meio da intercorporeidade bebê-parceiros. Estes últimos poderiam tanto ser adultos, como pares de idade. No drama das relações estabelecidas, concretizavam-se significados sobre a posição do bebê naquele espaço, o papel a ser assumido pela criança e aquele esperado da criança, exigindo recursos diferenciados da mesma. Significando e sendo significada, atravessada e constituída pela emoção e afetividade em construção, de forma situada e relacional, alguns padrões comportamentais e relacionais foram identificados quanto ao modo como a criança construia significações enraizadas na cultura, constitutivas da sua subjetividade. 
Já o trabalho de Souza se debruçou no estudo das interpretações de crianças sobre contos populares. A autora considerou a importância dos símbolos e de processos de simbolização, os quais dão sentidos para sentimentos, situações de vida e angústias ligadas ao se desenvolver. Ainda, destacou que aqueles contribuem com elementos para enfrentar as angústias como parte da vida e não como tragédias e rupturas de sentido. Com isso, a autora tomou como eixo a análise de falas de crianças, a partir de contos de fadas. Para ela, estes representariam uma intermediação simbólica entre o mundo interno e a realidade, e são entendidos como interferindo nas crenças infantis e na compreensão da mágica no âmbito das interpretações. Segundo Souza, as crenças vão num continuum, do pensamento pré-lógico ao lógico, com diversas operações cognitivas e emocionais inseridas. Portanto, o estudo das crenças permite conhecer a qualidade das representações. E estudos sobre as representações - incluindo-se aí os contos populares - poderiam permitir o acesso ao desenvolvimento psicológico, cognitivo e afetivo, estes tendo relações com também a idade e as vivências da pessoa, em que as qualidades das estruturações variam ao longo da vida e sofrem influência de aspectos contextuais. Também por meio de diferentes pesquisas (algumas das quais em intercâmbio com pesquisadores estrangeiros), Souza analisou a construção de significados por crianças de quatro a 11 anos, partindo da epistemologia genética de Piaget. Como a autora afirmou, Piaget se interessou particularmente pela capacidade de a criança simbolizar o mundo e a si mesmo, tendo foco central na questão do desenvolvimento da inteligência e da construção do conhecimento. Porém, como novidade aqui, a autora trouxe concepções de Piaget sobre a afetividade nas interpretações dos referidos processos, já que ele mesmo afirmou que a afetividade está intimamente relacionada aos interesses e preferências, além dos valores enquanto expansões do eu. Souza discutiu, ainda, diferentes aspectos relacionados ao contexto sócio-cultural e às práticas educativas parentais como participando dos processos em questão.

Já Leme, Carvalho e Jovelevithz, considerando o alto índice de violência entre adolescentes no país que vem sendo atribuído à sua educação, desenvolveram pesquisa que buscou compreender a percepção dos jovens sobre a opinião dos pais relacionada à seleção de estratégia de resolução de conflitos interpessoais. Como base conceitual e guia para análise, conceberam uma ampla gama de variáveis contribuindo para constituir a situação. Dentre elas, destacam questões contextuais dos adolescentes (como condição socioeconômica da família, organização familiar e número de pessoas e experiências no ambiente domiciliar). Consideraram também a suposta crise de autoridade da família e da escola, elementos culturais (como valores mais individualistas ou coletivistas, modos de disciplinarização) e modos de afetividade (relações de amizades e de poder).

A partir da perspectiva dos préadolescentes, utilizando-se de questionário, foram apresentadas dez situações de conflito hipotéticas com colegas, amigos e familiares, em que seriam o alvo das provocações. A meta seria ver estratégias de resolução (submissão, coerção, mistas e negociação) e buscar identificar como eles imaginariam a opinião dos pais frente às situações. No artigo, particularmente foram exploradas a situação familiar, o lazer (com quem?), as estratégias de resolução e a opinião dos pais.

Finalmente, Leite tratou do papel da afetividade nas práticas pedagógicas desenvolvidas por professores em sala de aula. Para ele, a mediação pedagógica também é de natureza afetiva. E ele entende que, a depender da forma como é desenvolvida, tal mediação produz impactos afetivos positivos ou negativos na relação que se estabelece entre os alunos e os conteúdos escolares. Leite assumiu, assim, que as relações que se estabelecem entre o sujeito, o objeto de conhecimento e o agente mediador são marcados profundamente pela dimensão afetiva, com impactos subjetivos no sujeito, resultando em aproximações e distanciamento. Seu eixo buscou romper com a histórica concepção dualista nas relações de ensino e aprendizagem, em que haveria predomínio da razão sobre a emoção e que o conhecimento só seria possível através da razão. Neste sentido, buscou identificar e analisar algumas práticas/mediações, decisões pedagógicas planejadas e desenvolvidas por professores e seus impactos afetivos nas relações entre aluno e conteúdos escolares.

Leite apresentou um estudo de caso, conduzido com base em teorias centradas em concepção materialista dialética, em que o desenvolvimento é entendido pelas relações 
que mantém com sua cultura, no seu ambiente social. A partir de entrevistas e autoscopia com os professores, desenrolou vários pontos de discussão como a escolha dos objetivos de ensino, a decisão sobre o início do processo de ensino, a organização dos conteúdos de ensino, a escolha dos procedimentos e atividades de ensino e a escolha dos procedimentos de avaliação do ensino. Nesse bojo, destacou a afetividade que envolve vivências e formas de expressão mais complexas com a apropriação dos processos simbólicos da cultura, atingida pela mediação cultural.

Os quatro artigos tiveram, assim, como meta destacar o lugar e o papel da afetividade em processos relacionais e desenvolvimentais, que não se reduzem à infância, mas circunscrevem ações e relações ao longo de toda a vida - incluindo-se aí a pré-adolescência e a vida adulta. Os artigos abordaram a temática, ainda, a partir de perspectivas teóricometodológicas diversas, todas considerando o lugar do outro, das relações, do contexto e da cultura na significação e simbolização que emergem nos processos.

\section{Referências}

Amorim, K. S., Costa, C. A., Rodrigues, L. A., Moura, G. G., \& Ferreira, L.D. (2012) O bebê e a construção de significações, em relações afetivas e contextos culturais diversos. Temas em Psicologia, 20(2), 309326.
Esperidião-Antonio, V., MajeskiColombo, M., Toledo-Monteverde, D., Moraes-Martins, G., Fernandes, J. J., Assis, M. B., et al. (2008). Neurobiologia das emoções. Revista de psiquiatria clínica, 35(2), 55-65.

Galvão, I. (2001). Expressividade e emoção: ampliando o olhar sobre as interações sociais. Revista Paulista de Educação Física, supl.4, 15-31.

Garvey, A., \& Silva, M. (2010). Desenvolvimento da comunicação, identidade e emoções na infância: contribuições das perspectivas relacional e dialógica. Educar, 36, 55-64.

Leite, S. A. da S. (2012) Afetividade nas práticas pedagógicas. Temas em Psicologia, 20(2), 355-368.

Leme, M. I. S., Carvalho, A. M., \& Jovelevithz, I. (2012) Opinião dos pais e resolução de conflitos por pré-adolescentes. Temas em Psicologia, 20(2), 337-354.

Mendes, D. M. L. F., \& Seidl Moura, M. L. (2009b). Expressões faciais de emoção em bebês: importância e evidências. Estudos de Psicologia, 9(2), 307-327.

Oliva, A. D., et al. (2006). Razão, emoção e ação em cena: a mente humana sob um olhar evolucionista. Psicologia: Teoria e Pesquisa, 22(1), 53-61.

Souza, M. T. C. C. (2012) Os simbolismos infantis e a mágica dos contos: uma compreensão piagetiana. Temas em Psicologia, 20(2), 327-335. 